\title{
Cigarette advertising on taxicabs in Boston, Massachusetts (USA)
}

\begin{abstract}
Objective-To examine the frequency of tobacco advertisements on taxicabs within Boston, Massachusetts (USA).

Design-At seven locations throughout Boston, an observer counted all taxicabs over 30-minute periods in December 1995. Main outcome measures-Confirmed sightings of taxicabs with cigarette advertisements were recorded with information collected on the cigarette brand and taxicab company.

Results-A total of 314 taxicabs were observed over 210 minutes of observation time, including $127(40.4 \%)$ with cigarette advertisements. Taxicabs with cigarette advertisements were seen once every 1.65 minutes on average, with Marlboro as the most frequently advertised brand (69 of 127 advertisements, $54.3 \%$ ). Less affluent locations were serviced by greater proportions of taxicabs carrying cigarette advertisements compared with more affluent locations (odds ratio $=2.08,95 \%$ confidence interval $=1.18-3.68)$.

Conclusions-Taxicabs represent a major form of exposure to cigarette advertising in Boston.
\end{abstract}

(Tobacco Control 1997;6:128-130)

Keywords: advertising, taxicabs, industry

\section{Introduction}

Tobacco companies spend more than $\$ 5$ billion per year in advertising their products throughout the United States. ${ }^{12}$ Advertisements frequently target children, women, and minorities. ${ }^{3-8}$ Cigarette billboards have been shown to be more visible and more common in low-income neighbourhoods. ${ }^{5}$

Among the various forms of tobacco advertising, taxicabs present a uniquely effective vehicle by which tobacco companies can promote their products throughout major metropolitan cities. As noted by Davis and Kendrick, ${ }^{9}$ the Surgeon General's warning is impossible to read on a moving cab. Out of 100 cabs with cigarette advertisements viewed from a park bench in New York City, not a single warning message could be read, whereas the brand name and notable imagery could be identified in $100 \%$ and $95 \%$ of the advertisements, respectively. This is consistent with a study of adolescents' recall and eye tracking of cigarette advertisements, indicating that only $8 \%$ of viewing time is devoted to the warning message. ${ }^{10}$ The cigarette advertisements atop taxicabs stand out in a line of traffic and can be seen from a distance.
Exposure to cigarette advertising on taxicabs has never been subjected to any formal research methodology. The measurement of cigarette advertisements on taxicabs, like those done for billboards and magazines, is a highly useful environmental indicator for community risk factor assessments. ${ }^{11}$ In our study, we examined the frequency of tobacco advertisements on taxicabs within Boston, Massachusetts.

\section{Methods}

Seven locations for exposure measurements were selected throughout the city based on traffic volume, geographic diversity, and convenience. These locations represent a small share of total traffic volume in Boston, recognising the difficulty in quantifying traffic patterns and pervasiveness at a single point in time, regardless of the sampling frame. Five locations included the main entrance of Massachusetts General Hospital, two different major downtown shopping and business districts at Downtown Crossing and the Back Bay, the central campus of Boston University, and a large supermarket in a residential section of Boston. The final two locations were in Roxbury, a proportionally less affluent and predominantly black neighbourhood of Boston. These locations included Madison High School and a street corner at Franklin Square.

For each location, a single observer stood on the sidewalk (pavement) near the street where passing vehicles could be readily identified. Taxicabs passing the observer were tallied over a 30-minute period. Only confirmed sightings of taxicabs and their advertisements were recorded. Standing cabs - that is, parked along the street waiting for a customer-were counted only if they were visible to the observer. Additional information on the cigarette brand (Marlboro, Kool, Camel, Newport, Parliament, Merit, or Carlton) and taxicab company was gathered.

All data were collected on a single weekday between 10 am and $4 \mathrm{pm}$ in December 1995 as a compromise between the rush hour and nonrush hour periods, for a conservative estimate of cigarette advertising exposure.

Descriptive statistics were collected on the number of taxicabs and the proportion of cabs carrying tobacco advertisements, and the brands advertised. We used Fisher's Exact $\chi^{2}$ statistic to compare the proportions of cabs with particular cigarette brands in more vs less affluent locations, also computing odds ratios and $95 \%$ confidence intervals (CIs). 
Table 1 Cigarette advertising on taxicabs in Boston, Massachusetts for a 30-minute period

\begin{tabular}{lcr}
\hline Location & Total number of cabs & $\begin{array}{l}\text { Cabs with cigarette } \\
\text { advertising } \\
n(\%)\end{array}$ \\
\hline Massachusetts General Hospital & 23 & $5(21.7)$ \\
Downtown Crossing shopping district & 25 & $12(48.0)$ \\
Back Bay commercial/business district & 88 & $36(40.9)$ \\
Boston University central campus & 66 & $18(27.3)$ \\
Star Market & 52 & $23(44.2)$ \\
Madison High School & 29 & $17(58.6)$ \\
Franklin Square & 31 & $16(51.6)$ \\
Totals & 314 & $127(40.4)$ \\
\hline
\end{tabular}

\section{Results}

Table 1 lists the seven locations selected for the study and the numbers and percentages of taxicabs with cigarette advertisements. Overall, 127 taxicabs with cigarette advertising were sighted during 210 minutes of observation time. This is equivalent to a taxicab with cigarette advertising potentially being seen by a stationary individual once every 1.65 minutes. Proportionally more of the taxis in less affluent sites (33 of 60 taxicabs, 55\%) had cigarette advertisements compared with taxis in more affluent sites (94 of 354, 37\%).

Marlboro was by far the most frequently advertised cigarette brand on taxicabs, comprising 54\% (69 of 127) of all cigarette advertisements. This is equivalent to a Marlboro advertisement being seen on a taxicab once every three minutes. At all seven locations, Marlboro was the most frequent brand, and was twice as common as the second most frequent brand at six of seven locations. Other brands advertised included Kool (17 taxicabs, $13.4 \%$ of all taxicabs with tobacco advertisements), Camel (12, 9.4\%), Newport $(11,8.7 \%)$, Parliament $(11,8.7 \%)$, Carlton (5, $3.9 \%$ ), and Merit (2, 1.6\%).

Sixteen different taxicab companies displayed cigarette advertisements. Six taxicab companies were responsible for $89.8 \%$ (114 of 127) of all advertisements, with three taxicab companies accounting for nearly threequarters of all cigarette advertising, with $35.4 \%, 20.5 \%$, and $16.5 \%$ shares, respectively. Not all taxicabs from a single company carried cigarette advertising. Companies also did not exclusively advertise particular brands of cigarettes.

Table 2 compares taxicabs seen in the five more affluent locations in Boston with the two less affluent areas of Boston. More total taxicabs were seen per minute in highly affluent locations (1.69 taxis/minute) compared with less affluent locations (1.00 taxis/minute). Ninety-four taxicabs with cigarette advertising were seen in more affluent areas (one every 1.60 minutes) compared with
Table 3 Odds ratios and 95\% confidence intervals comparing the proportions of taxicabs with particular cigarette brands in less vs more affluent locat $\theta_{\text {h }}$

\begin{tabular}{|c|c|c|}
\hline & & 0 \\
\hline & Odds ratio & О $95 \% C I$ \\
\hline All cigarette brands & 2.08 & 层 $1.18-3.68$ \\
\hline Proportions of brands displayed & & 음 \\
\hline Marlboro & 1.01 & $\Rightarrow 0.46-2.24$ \\
\hline Kool & 2.26 & ஸ $0.78-6.54$ \\
\hline Camel & 0.24 & 厂 $0.03-1.90$ \\
\hline Newport & 1.08 & $0.27-4.32$ \\
\hline Parliament & 1.08 & $\stackrel{\sigma}{\sigma} 0.27-4.32$ \\
\hline Kool plus Newport & 1.72 & $\stackrel{\bar{\omega}}{\supset} 0.70-4.21$ \\
\hline $\mathrm{CI}=$ confic & & ڤ) \\
\hline
\end{tabular}

33 taxicabs in less affluent areas $\vec{\phi}$ one every 1.82 minutes).

As table 3 shows, less affluen $\vec{\omega}$ areas had greater proportions of taxicabs wi i cigarette advertisements than more affluent areas (odds ratio $(\mathrm{OR})=2.08,95 \% \mathrm{CI}=1.18-3.68)$. Kool and Newport, brands traditionallyoodvertised to black consumers, ${ }^{12}$ also comprised a greater proportion of brands displayed on-taxicabs in less affluent areas compared with mere affluent areas $(\mathrm{OR}=1.72 ; 95 \% \mathrm{CI}=0.70$ - .21 ).

\section{Discussion}

This study provides preliminary ergdence that taxicabs may be a significant 乏source of exposure to cigarette advertiong, with someone walking potentially exposed once every $99 \mathrm{~s}$.

Taxicab prevalence is subject to väriations by season, day of the week, and hour 3 of the day. Furthermore, because our results axe based on a convenience sample, they must be interpreted cautiously with regard their generalisability. Still, more taxicabs ould have been counted if the data had beea collected

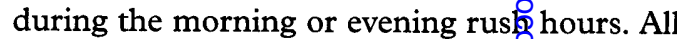
advertisements, including those fo are also conveniently lit so as to bisible at night.

The frequency of exposure t⿳亠口冋. cigarette advertising on taxicabs in Boston w\&s very high no matter where a person looked. About $40 \%$ (127 of 314) of all taxicabs seen in Boston carried a tobacco advertisement. It addition, standing taxi lines, which are seen roughout the city, are equivalent to small ज्stationary cigarette billboards.

A notable finding of this studf was the tendency for greater proportions of be carrying cigarette advertisemeñnts in less affluent locations. Despite the lowe taxicabs in less affluent areas, the rapes of exposure to cigarette advertisements vir taxicabs were very similar (every 1.60 minues in more affluent areas $v$ s every 1.82 minựes in less affluent areas). In addition, this study suggests

Table 2 Cigarette advertising on taxicabs in Boston, based on the type of location

\begin{tabular}{|c|c|c|c|c|c|c|c|}
\hline \multirow[b]{2}{*}{ Location } & \multirow{2}{*}{$\begin{array}{l}\text { Total number of } \\
\text { cabs }\end{array}$} & \multirow{2}{*}{$\begin{array}{l}\text { Cabs with cigarette } \\
\text { advertising } \\
n(\%)\end{array}$} & \multicolumn{5}{|c|}{ Number (\%) of cabs among those with tobacco advertisem $\frac{\overline{2}}{\mathrm{~T}}$} \\
\hline & & & Marlboro & Kool & Camel & Newport & Parliament \\
\hline $\begin{array}{l}\text { More affluent* } \\
\text { Less affluent } t\end{array}$ & $\begin{array}{r}254 \\
60\end{array}$ & $\begin{array}{l}94(37.0) \\
33(55.0)\end{array}$ & $\begin{array}{l}51(54.3) \\
18(54.5)\end{array}$ & $\begin{array}{r}10(10.6) \\
7(21.2)\end{array}$ & $\begin{array}{c}11(11.7) \\
1(3.0)\end{array}$ & $\begin{array}{l}8(8.5) \\
3(9.1)\end{array}$ & $\begin{array}{l}8(8.5) \\
3(9.1)\end{array}$ \\
\hline
\end{tabular}

* Includes Massachusetts General Hospital, Downtown Crossing, Back Bay, Boston University, and Star Market.

† Includes Madison High School and Franklin Square. 
that brands such as Kool and Newport, used more heavily by black groups, may appear proportionally more often among advertisements in less affluent locations with greater black representation.

These results provide some evidence for the claim that the tobacco industry specifically targets cigarette advertisements based on demographic information about different neighbourhoods in the same city. In fact, advertising on top of taxicabs is done when a taxicab owner leases the roof to a contracted advertising agency, which controls all advertisements. However, if an advertiser wanted to target certain parts of Boston, the advertising agencies know which taxicab companies tend to cover those areas, including areas of high and low affluence (personal communication with advertising agency manager, 30 October 1996).

The extent to which people actually notice and "read" cigarette advertisements on taxicabs was not assessed in our study, and is an area where research is needed. Those who use or experiment with tobacco might be expected to pay particular attention to cigarette advertisements on taxicabs. In 1993, $22.3 \%$ of adults in Boston were current cigarette smokers, while $17 \%$ of $12-17$ year olds in Massachusetts reported having experimented with cigarettes. ${ }^{13}$ Those who do not use tobacco (potential users) may also be targets of advertising on taxicabs and in other media.

Regulations on tobacco advertising promulgated by the US Food and Drug Administration do not restrict advertisements on taxicabs. ${ }^{14}$ Cigarette advertising on taxicabs occurs in most other major metropolitan areas in the United States, although we are aware of no other observational data that have been published. The potential for a massive population exposure to cigarette advertising through taxicabs should be studied further in metropolitan areas across the country.

This research was supported by Institutional National Research Service Award HL-07575 from the National Heart, Lung, and Blood Institute.

1 US Department of Health and Human Services. Preventin tobacco use among young people. A report of the Surgeon Gen tobacco use among young people. A report of the Surgeon General. Atlanta, Georgia: Public Health Service, Centers for Disease Control and Prevention, Office on Smoking and
Health, 1994 (US Government Printing Office No S/N Health, 1994 (US

2 US Federal Trade Commission. Report to Congress for 1994 Pursuant to the Federal Cigarette Labeling and Advertising Act. Washington, DC: Federal Trade Commission, 1996.

3 Pierce IP, Lee L, Gilpin EA. Smoking initiation by adolescent girls, 1944 through 1988. An association with targeted advertising. $¥ A M A$ 1994;271:608-11.

4 Pierce JP, Gilpin E, Burns DM, et al. Does tobacco advertising target young people to start smoking? Evidence from tising target young people to start smo

5 Mitchell $O$, Greenberg $M$. Outdoor advertising of addictive products. $N \mathcal{F}$ Med 1991;88:331-3.

6 Ammerman SD, Nolden $M$. Neighborhood-based tobacco advertising targeting adolescents. West $\mathcal{f}$ Med 1995; 162:514-8

7 Guthrie B. Tobacco advertising near schools. BMf 1994 308:658.

8 Warner KE, Goldenhar LM, McLaughlin CG. Cigarette advertising and magazine coverage of the hazards of smok ing: a statistical study. $N$ Engl $¥$ Med 1992;326:305-9.

9 Davis RM, Kendrick JS. The Surgeon General's warnings in outdoor cigarette advertising: Are they readable? $¥ A M A$ 1989;261:90-4.

10 Fischer PM, Richards JW, Berman EJ, Krugman DM Recall and eye tracking study of adolescents viewin tobacco advertisements. $\mathscr{f} A M A 1989 ; 261: 84$

11 Cheadle A, Wagner E, Koepsell T, Kristal A, Patrick D. Environmental indicators: a tool for evaluatin community-based health-promotion programs. Am $\mathcal{\exists}$ Prev Med 1992;8:345-50.

12 Davis RM. Current trends in cigarette advertising and marketing. $N$ Engl f Med 1987;316:725-32.

13 Biener L, Fowler FJ Jr, Roman AM 1993 Massachusetts Tobacco Survey: Tobacco use and attitudes at the start of the Massachusetts Tobacco Control Program. Boston, MassachuMassachusetts Tobacco Control Program. Boston, Massachu-
setts: Center for Survey Research, University of Massachusetts, Boston, 1994

14 US Food and Drug Administration. Regulations restrictin the sale and distribution of cigarettes and smokeless tobacco to protect children and adolescents; final rule. Federal Register 1996;61:44395-618.

\section{Tobacco in history \\ HOW EMPLOYERS FEEL TOWARDS CIGARETTE SMOKERS}

Here is an automobile company's attitude

\section{NOTICE}

"Cigarette smoking is acquiring a hold on a great many boys in our community . . . . Since it is such a bad practice and is taking a hold upon so many people, we think it is a disgrace for a grown man to smoke cigarettes, because it is not only injurious to his health, but it is such a bad example to the boys.

"Boys who smoke cigarettes we do not care to keep in our employ. In the future we will not hire anyone whom we known to be addicted to this habit. It is our desire to weed it entirely out of the factory just as soon as practicable. We will ask every- one in our factory, who sees the seriousness of this habit to use their influence in having it stamped out.

"We have two objects in interesting ourselves to this matter; First, to help men and boys; second, we believe that men who do not smoke cigarettes or frequent the saloon can make better automobiles than those who do."

-Henry Ford, 1916. In: The case against the little white slaver (reprinted by the Historical Society of Michigan in 1992). 